\title{
Hibridación genérica en Gonzalo Millán. Lectura del diario íntimo Veneno de escorpión azul (2007)
}

\author{
Generic hybridization in Gonzalo Millán. \\ Reading of the intimate journal Veneno de escorpión azul \\ (2007)
}

\section{Macarena Roca Leiva}

Universidad Adolfo Ibáñez. Santiago, Chile

mroca@uai.cl

\section{MILLÁN Y EL PENSAMIENTO RIZOMÁTICO}

iario intimo (2007) de Gonzalo Millán transita, en el interior de su textualidad genérica, entre tipologías de escritura conocidas como canónicas y referenciales: poesía, narrativa, bitácora, aforismos y formas fragmentarias e inclasificables. La existencia de este texto anfibológico exhibe diferentes modos de enunciado y enunciación, no sólo por las formas genéricas que participan, sino por la discontinuidad y desplazamientos que se producen entre estos estilos discursivos. Esto genera un texto ambiguo desde el punto de vista del lugar de escritura y, a la vez, un campo exploratorio de los (des)lindes en los que el "yo" enunciativo experimenta la construcción diaria de un texto performativo sobre la paulatina disolución del "yo" escribiente1.

Millán creó, como poeta y artista visual, una obra heterogénea en sus técnicas y formatos, pero con una conciencia macrotextual que permite rastrear la unidad en torno a las problemáticas trabajadas. Produjo en las fronteras

\footnotetext{
${ }^{1}$ También el llamado hipertexto (o multilinealidad artística) se encuentra emplazado en el fenómeno de la hibridez o disolución de géneros discursivos, sin embargo esta concepción es utilizada mayormente en ámbitos tecnológicos, informáticos y periodísticos.
} 
de sus temáticas, encontrándose permanentemente en los límites de los sistemas aludidos: democracia-dictadura, vida-muerte, mirada-automirada ${ }^{2}$. A la vez, la ejecución de sus temas a partir de lenguajes alternos o subsidiarios a la escritura, como la inclusión del dibujo y los deslindes entre palabra e imagen, tan propios de su poesía visual y plástica, proyectan un amplio y nutritivo marco categorial.

La construcción rizomática es analógica a una escritura de líneas, detenciones y fugas paralelas; siendo, cada una de estas condiciones, multiplicidades en su constitución. Un libro, en cuanto rizoma o "composición maquínica”, no responderá:

A la pregunta sobre lo que quiere decir, en cuanto significado o significante; tampoco deberá tratarse de comprender nada en él. Únicamente vale preguntar con qué funciona; en conexión de qué hace pasar o no intensidades; en cuáles multiplicidades introduce y metamorfosea la suya; con qué cuerpos sin órganos hace converger el suyo (Deleuze y Guattari, 2001: 8-9).

Un libro debe ser "máquina de guerra" y no "aparato de Estado", es decir, no presentar la imagen del mundo, sino que hacer rizoma con él (Deleuze y Guattari, 2001: 16). Los principios presentes en este sistema son señalados como: Conexión y Heterogeneidad, los cuales explican que "todos los puntos de un rizoma pueden -y deben- ser conectados con otro cualquiera” (12), ya que no es reductible a un orden lingüístico, sino que propicia múltiples conexiones políticas, culturales o económicas. La Multiplicidad, tercer principio del sistema, es por tanto aquella escritura que deja de tener relación ordenativa y jerárquica con el Uno. Las multiplicidades deben ser siempre eslabones de tubérculos "y denunciar las seudomultiplicidades arborescentes" (14). La llamada Ruptura asignificante se integra a los principios anteriores para explicar que un rizoma tiene, inherentemente, la condición de corte y discontinuidad, entendiendo esto como quiebres no canceladores, sino interrupciones que producen nuevas continuidades y asociaciones. Finalmente, Cartografía y Calcomanía son los principios que establecen, desde su diferencia, que un rizoma "no responde a modelos estructurales o generativos [ya que] es completamente ajeno a la idea de eje genético o es-

${ }^{2}$ El epígrafe del Diario, poema del mismo Millán, revela el bifrontismo y multipropósito de la escritura: Diario morir / Diario vivir; Diario de Vida / Diario de muerte; Hechos consumados / Deshechos consumados (...); Poemas a la muerte / Poemas de despedida de la vida (...); Testamento / Preparación para el viaje (7). 
tructura profunda" (21). Toda la lógica del árbol es una lógica del calco y de la reproducción infinita, en cambio el mapa posee innumerables entradas:

El mapa no reproduce un inconsciente cerrado sobre sí mismo; lo construye, es decir, contribuye a la conexión de los campos (...), un mapa es cuestión de ejecución; mientras que el calco remite siempre a una presunta competencia (Deleuze y Guattari, 2001: 22).

Por lo tanto, un texto rizomático no es meramente una obra abierta, llana a intertextualidades y principios teóricos de la recepción, sino una nueva noción de obra que se emparienta con principios fenomenológicos sobre episteme. En él no hay dicotomías ni dualismos, por ello no se escoge ni define la realidad y su representación; lo que sería un signo de poder nominal, propio del libro entendido en términos clásicos. La (de)construcción rizomática apuesta por las permutaciones y utilizaciones que el lector hará del texto, entendiendo que "éstas no son nunca interiores al libro, sino que dependen de las conexiones con el exterior" (Deleuze y Guattari, 2001: 39). Por todo ello, para el pensamiento rizomático, un libro es experimentación, no significación, ya que debe formar máquina con alguna cosa.

El texto ya no es un microcosmos ni una imagen simbólica y orgánica del mundo ${ }^{3}$, sino un sistema desatomizado en donde dejan de operar marcadores de poder, ejes centrales y categorizaciones. Desde la vanguardia histórica, la nueva obra de arte ya no remite a un todo orgánico, sino a un montaje de partes que se constituyen en un nuevo -y plural-orden. Millán explicita el artificio de la obra y con ello revela el soporte material y su mediación con la realidad. La escritura sobre la muerte no es una representación abstracta ni enmascaradora de ella, sino una configuración material que intenta patentizar la percepción del acabamiento:

Martes 12 de septiembre, Santiago (...). Escribo en cuadernos de 100 hojas/ matemáticas cuadro chico $5 \mathrm{~mm} /$ con lápices japoneses Pilot de tinta gel/ negro y azul, los fecho. / Junto tres cuadernos llenos y los empasto/ con cintas plásticas adhesivas (Millán, 2007: 264).

La acción que detalla Millán evidencia el lugar material en el que se recoge y objetualiza la escritura. En Veneno de escorpión azul estamos ante una imagen sensible de la contención de la muerte.

${ }^{3}$ Ver Burger (1987). 


\section{HIBRIDACIÓN EN VENENO DE ESCORPIÓN AZUL}

La hibridez en el diario de Millán se vincula a un pensamiento rizomático. No es un objetivo (pre)meditado, como se encuentra en gran parte de la escritura de la segunda mitad del siglo $\mathrm{XX}^{4}$, sino una consecuencia histórica, artística y, a la vez, personal del proceso de reconocimiento de la muerte y la comprensión del acabamiento del tiempo; del tiempo del cuerpo, de la poesía y de la voz en el sujeto escritor. Éste, el artista de la posmodernidad, decide vivir "la antesala de la tumba" (Millán, 2007: 22) ajeno al esteticismo con que, durante décadas, la modernidad ha evitado su esencial obscenidad ${ }^{5}$ y antinaturalidad ${ }^{6}$. Millán funda su discurso en una multiplicidad de voces enunciativas que escogen diversos discursos para su decir. La conexión entre ellas y sus asignificantes rupturas nos entregan un texto híbrido en su formato el cuál sólo puede ser significado desde la noción de diario íntimo. Este género acepta una multiplicidad de tipos de escritura; inclusive, formatos plásticos incorporados y montados en su trayecto (fotografías, postales, trozos de papel), siendo la única condición organizativa la 'fechación' de los días, "una cláusula de apariencia liviana pero temible: [el respeto al] calendario" (Morales, 2001: 115). El diario de vida -y la escritura íntima- ha dejado de ocupar un lugar menor o referencial para iniciar su participación en la categoría de género principal y autónomo. Se describe por ser un:

Registro circunstanciado, la crónica de una conciencia íntima (...) abierta a toda clase de solicitaciones y estímulos imprevistos de la vida cotidiana, $\mathrm{y}$ a las reacciones de una conciencia que construye sus respuestas (Morales, 2001: 85-6).

Una inscripción de escritura abierta a las impresiones, imágenes y reflexiones que diariamente un sujeto produce; en donde la emoción y la razón, interrogándose a sí mismas y creando continuidades y rupturas en

\footnotetext{
${ }^{4}$ Históricamente, el texto híbrido, cuya voluntad original responde al caos o revolución, que desea provocarse en la escritura y en su recepción se relaciona con el cambio que el libro -junto a otros soportes artísticos- ha tenido en cuanto objeto de intelección. La incorporación de nuevas categorías genéricas tuvo lugar con el término de discursos o representaciones hegemónicas y universales, las cuales fueron ampliadas a nuevas conceptualizaciones artísticas y estéticas. Las reproducciones técnicas, construcciones fragmentarias y montajes de formas son posibilitados con la vanguardia europea la cual reflexionó críticamente sobre la institución artística y una nueva categoría de obra de arte. Ver Noguerol (1999).

${ }^{5}$ Ver Baudrillard (1993).

${ }^{6}$ Ver Jankélévitch (2006).
} 
la configuración de las ideas, genera una enunciación dispar, pero a la vez inserta en un contexto más cercano. El matiz sicológico ${ }^{7}$ que está referido en las marcas textuales empleadas señalaría el contenido del pensamiento del autor; en este caso, la intención de convivir con el proceso protomortuorio, el intento de corporeizar lo irrepresentable: "Ahora, el placer de comerte una simple hallulla con mantequilla de pie en una cocina por la tarde" (Millán, 2007: 136).

La enunciación, por lo tanto, es el acontecimiento histórico que constituye, por sí misma, la aparición de un enunciado, "es el hecho de que una oración haya sido realizada" (Ducrot, 1984: 135). Ésta es el paroxismo del pensamiento ante la inminente escritura. No sólo está implicada en el conjunto de movimientos articulatorios de la lengua mediante el habla, sino que es previa a la existencia del enunciado. ¿Cuál es la enunciación que promovería los enunciados de este diario? La prolongación de la vida mediante la datación de la pre-muerte, la extinción del sujeto y su escritura, la confianza en la palabra, la aprehensión de lo inaprensible, la conciencia sobre el propio cuerpo. Enunciado y enunciación nos enseñan una "muerte sobre", en donde el autor, con gran lucidez, toma conciencia sobre el abandono de la corporeidad:

El cáncer es el destructor de la ignorancia de mi cuerpo (32).

Creo tener otra comprensión, una consideración desconocida. El peso físico de las cosas (comunes y corrientes) me maravilla: un frasco de vidrio con azúcar tapado con un tapón de corcho; la constancia deleitosa del tacto al secarse las manos (mojadas) con una toalla (22).

Lo mejor (de vivir) es respirar sin darse cuenta (Millán, 2007: 113).

En los estudios de lingüística moderna, alocutario y auditor han sido considerados meras variantes de la noción de receptor. Sin embargo se distinguen en la psicolingüística, por la dirección o destinación que toma el acto de habla. El alocutario de un enunciado es aquel a quien el locutor declara dirigirse; el auditor, en cambio, es todo tercero que recibe el enunciado. En el género diario el autor es su propio alocutario, ya que la redacción de éste nos muestra una escritura replegada sobre sí, donde el destinatario es inexistente (en términos de una otredad). Por ello, la escritura es un movimiento reflexivo en donde el sujeto hace y despliega su pensamiento para sí mismo:

\footnotetext{
${ }^{7}$ Ver Ducrot (1984).
} 
¿Qué escrituras han sido, sin esnobismo, realmente importantes en tu vida? - Proust (...) ¿Por qué? Memoria. - Flaubert, por su realismo escrupuloso (...) - Blake, por su videncia evidente, efectiva, mayor que la de Rimbaud, preferible a la de Hölderlin y Novalis (Millán, 2007: 54).

De esta forma, Veneno de escorpión azul se nos presenta como un:

Diario de vida y muerte, bitácora / terminal, caja negra que sobrevive/ al desastre. Las últimas palabras. / Un género sobreviviente postrero. / Los borradores de un epitafio. / Los altibajos gráficos de un ficha clínica (Millán, 2007: 24).

\section{LENGUAJE Y CONCIENCIA DE MUERTE}

La escritura sobre la muerte, para Jankélévitch (2006), ofrece el ejercicio acrobático, apasionante, de un pensamiento que, no pudiendo aceptarla, se aproxima a ella al máximo. La muerte es el eje temático ante el cual, variados registros literarios buscan formalizar la (no) imagen de ella. Millán se configura un imaginario personal que le permita dar forma inteligible a la muerte y a su presencia actual:

El cáncer es una verruga interna y gigante que crece en secreto dentro de uno (91).

Mi cáncer no es un cangrejo, es una pancora morada oculta entre lóbulos rocosos musgosos (65).

Fabrico un tumor con piezas infantiles de Lego, un cáncer octogonal, una masa angulosa con aristas y botones de plástico y varios huecos (Millán, 2007: 216).

Si la muerte es la angustia por lo irrepresentable, ¿qué se puede decir de la transformación más grande del mundo? No es incluso una transformación, dice Jankélévitch, ya que ésta es el pasaje de una forma a otra, tal como lo indica la palabra, y la muerte es el pasaje a la "ausencia de la forma". Entonces esta idea es irrepresentable, ya que "no es posible establecer una relación empírica con ella" (2006: 101). Sin embargo, Millán produce un preestreno de la muerte en donde logra hacer experimental su existencia. Si el propio lenguaje no está hecho para expresar la muerte, ya que todas las palabras de las que uno se sirve son términos concretos, como, el "otro mundo" o "más allá de la vida”, (Jankélévitch, 2006: 100), es posible, mediante un acerca- 
miento a la muerte, desde el aquí y ahora, dar forma -aún así precaria- al acabamiento del individuo:

¡Qué se yo si habrá luz y sombra o nada! Hasta aquí llego yo con mis palabras sublunares. El más allá precisa otras lenguas, con impensados sonidos y vocabularios. ¡Qué se yo si me espera otro mundo, un mundo nuevo detrás de otro! (Millán, 2007: 26).

En un diario se registran las experiencias cotidianas y las reflexiones que éstas sugieren; por ello los "objetos domésticos para apoyar la mirada" (Morales, 2001: 113) en Veneno... parapetan el espacio privado: el periódico, el paquete de cigarrillos, las galletas. La muerte se hace corporeidad, se objetualiza. No sólo es configurada por la palabra, sino por los objetos sobre los cuales se detiene la mirada: "Hora del gotario, mi amarga mini clepsidra" (Millán, 2007: 97). La sujeción al calendario es radicalizada en el texto de Millán, ya que además se incorporará la presencia fatídica del reloj. La inclusión de esta medición nos otorga numerosas marcas de enunciación: horas, minutos, horarios de comidas, colación y trabajo, llegadas de periódicos y correspondencias, llamadas telefónicas, partidos de fútbol, caminatas, desvelos. Toda la máquina diaria de la vida. La muerte así abordada se torna tangible; tomando forma en las extenuantes dataciones:

Miércoles 07 de junio, 2006 Santiago. Horas: 11.30 (...) 12:10 (...), 12:30 (...), 12: 45 (...) (43).

El tiempo se ensancha y prolonga en medio de inacabables detenciones o pausas. Por ello, el paratexto del diario se configura como parte de la metaforización del proceso. El tiempo, latamente desplegado, hace extenuante y grávido su paso. Los días toman una espesura vacua que recuerda permanentemente la llegada de la muerte. "13:45/ --.---.---.---.--- CUALQUIER DÍA, EN CUALQUIER MOMENTO (Millán, 2007: 54).

La muerte en el Diario de Millán se teje con la periodicidad de lo cotidiano. La muerte está en la rutina, pero también en el acabamiento de ella. Se desplaza en el territorio de la vida mediante el uso rizomático del lenguaje:

13:00/ Onda tardehospital/de/ pezoavéliz/ mientas llueve en el Hospital del Tórax, /Onda Rilke, / una atroz y triste onda Rilke, / una melancolía desaforada (sin fondo) con una / camilla abandonada que se llueve / moja / empapa /en un patio (Millán, 2007: 41).

Cronografía, poesía, imagen, intertextualidad. Todo en función de la li- 
bertad enunciativa del preyacente. ¿Cuál es, entonces, la "máquina abstracta” (Deleuze y Guattari, 9) o macrotexto de Millán? Pareciera ser la mutación de las palabras, de la política, de las formas artísticas y del mismo sujeto que escribe sobre sí:

Todos los días que me restan soy alguien distinto. Todos los días que me restan intentaré ser alguien distinto al que fui y al que ya no seré (50). Yo soy otro, ese que hasta hace poco sin saberlo estaba enfermo, estaba enfermo sin saberlo, se pensaba sano sin saberlo (Millán, 2007: 62).

La mutación corresponde a un estado de vigilancia, a un movimiento de alerta en la que Millán desconfía hasta de sí mismo: "Lunes 05 de junio, 2006. Santiago (...) Pharmakon - Derrida / ouroboros" (40) ${ }^{8}$; una reflexión que sintetiza una perfecta actividad rizomática y de permanente (des)inscripción del poeta.

\section{CONCLUSIONES}

La obra de Millán es un movimiento perpetuo. Su diario íntimo no se encuadra en limitaciones de enunciado. Sus pensamientos fechados muestran una diversidad discursiva que permite descubrir distintos formatos morfosintácticos, siendo de preferencia la reflexión, la sentencia, el verso. Este texto heteromorfo reúne imágenes y divagaciones que nos exhiben un sujeto cuyo eje central de la escritura es la presencia irrevocable de la muerte; y desde ésta, la voz de la escritura avanza en medio de una variedad de registros los cuales se montan, tras el paso de los días, como fragmentos que hacen (ab)uso de las posibilidades del enunciar. Su escritura revela todo un mecanismo de metaforización: se verbaliza lo que no tiene nombre, se formaliza mediante la discontinuidad la detención e interrogación en la que el sujeto se encuentra. La hibridez genérica, constituyente del diario de Millán, y el fragmentarismo en su disposición y composición, articula un espacio de

8 'La palabra es para mí un 'pharmacon' un humor venenoso y a la vez vacuna, enfermedad y salud. Tengo una teoría viral de la poesía que sostiene que es imprescindible la mutación permanente de contenidos y formas. La retórica ya establecida comúnmente posee carácter entrópico. El reconocimiento público, el éxito de crítica y lectores, disimulan la 'cooptación', la anulación de los elementos críticos y subversivos. Tengo un enorme recelo por la palabra. La brevedad, la concisión, la claridad, la condensación permiten al texto defenderse del carácter parasitario y tergiversador del lenguaje. Las formas breves son antidiscursivas y buscan complicidad con el silencio sin retroceder al simbolismo" (García, 2006). 
ensayo y error, un ejercicio mortuorio. Su escritura es un ejemplo de (des) arraigo, de credibilidad ante lo increíble, el pivote del conocimiento de la propia desintegración; en palabras de Jankélévitch, "el movimiento de nada hacia ninguna parte" (2006: 11).

\section{REFERENCIAS}

Baudrillard, Jean. 1993. El intercambio simbólico y la muerte. Trad. Carmen Rada. Caracas: Monte Ávila.

Burger, Peter. 1987. Teoría de la vanguardia. Barcelona: Ediciones Península.

Deleuze, Gilles y Félix Guattari. 2001. Rizoma. Introducción. Trad. C. Casillas y V. Navarro. México: Coyoacán.

Ducrot, Oswald. 1984. El decir y o dicho. Trad. Sara Vasallo. Buenos Aires: Hachette.

García Javier. 2006. Gonzalo Millán habla codo a codo con la muerte. "Hay que salvar el pellejo como sea". [En línea]. Disponible en http://www. letras.s5.com/gm300806.htm. [Consulta: 10/08/2009].

Jankélévitch, Vladimir. 2006. Pensar la muerte. Trad. Horacio Zabaljáuregui, Buenos Aires: Fondo de Cultura Económica.

Millán, Gonzalo. 2007. Veneno de escorpión azul. Santiago: Ediciones Diego Portales.

Morales, Leonidas. 2001. La escritura de al lado. Géneros referenciales. Santiago: Cuarto Propio.

Noguerol, Francisca. 1999. "Híbridos genéricos: la desintegración del libro en la literatura hispanoamericana del siglo XX”. En Rilce 15, 1, pp. 239-50. 